\title{
Current status and prospects of plant genome editing in Australia
}

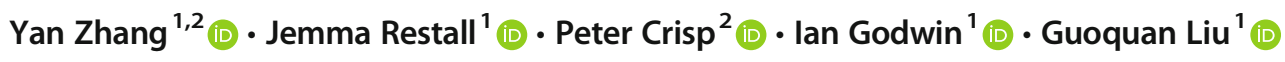

Received: 4 April 2021 / Accepted: 13 April 2021 / Published online: 24 May 2021 / Editor: Prakash Lakshmanan

(C) The Society for In Vitro Biology 2021

\begin{abstract}
Plant genome editing, particularly CRISPR-Cas biotechnologies, has rapidly evolved and drawn enormous attention all around the world in the last decade. The cutting-edge technologies have had substantial impact on precise genome editing for manipulating gene expression, stacking gene mutations, and improving crop agronomic traits. Following the global trends, investigations on CRISPR-Cas have been thriving in Australia, especially in agriculture sciences. Importantly, CRISPR-edited plants, classified as SDN-1 organisms (SDN: site-directed nuclease), have been given a green light in Australia, with regulatory bodies indicating they will not be classified as a genetically modified organism (GMO) if no foreign DNA is present in an edited plant. As a result, genome-edited products would not attract the onerous regulation required for the introduction of a GMO, which could mean more rapid deployment of new varieties and products that could be traded freely in Australia, and potentially to export markets. In the present review, we discuss the current status and prospects of plant genome editing in Australia by highlighting several species of interest. Using these species as case studies, we discuss the priorities and potential of plant genome editing, as well as the remaining challenges.
\end{abstract}

Keywords Plant genome editing $\cdot$ Australia $\cdot$ CRISPR-Cas $\cdot$ Transgene-free $\cdot$ Regulation $\cdot$ GMO

\section{Introduction}

The increasing demand on agriculture to remain sustainable and productive under changing climatic conditions and pressure from a growing global population could be aided through utilizing gene editing technologies. The development of target-specific genome engineering technologies, such as zinc finger nucleases (ZFNs), mega-nucleases, transcription activator-like effector nucleases (TALENs), and clustered regularly interspaced short palindromic repeats (CRISPR)/ CRISPR-associated protein 9 (Cas9), have paved the way for a new era of gene editing. CRISPR is a well-known bacterial immune defence system that forms the cornerstone for biotechnologies on CRISPR-Cas genome editing (Zhu et al. 2020). The breakthrough in genome editing was reported in

Yan Zhang and Jemma Restall contributed equally to this work.

Guoquan Liu

g.liu2@uq.edu.au

1 Centre for Crop Science, Queensland Alliance for Agriculture and Food Innovation, The University of Queensland,

Brisbane, QLD 4072, Australia

2 School of Agriculture and Food Sciences, The University of Queensland, Brisbane, QLD 4072, Australia the landmark article, which described that the CRISPR-Cas9 system is programmable for site-specific DNA cleavage in 2012 (Jinek et al. 2012). The high efficiency, simplicity, precision, and versatility of the CRISPR-Cas9 system have overshadowed previous genome editing biotechnologies such as ZFNs and TALENs (Gaj et al. 2013; Bortesi and Fischer 2015; Tachibana 2019). The rapid impact of CRISPR-Cas9 over just a decade has been recognized with the 2020 Nobel Prize in Chemistry awarded to two pioneer scientists Emmanuelle Charpentier and Jennifer Doudna for their discovery and development of CRISPR-Cas9 genome editing (Strzyz 2020).

Research on plant genome editing involving CRISPR-Cas has grown exponentially worldwide in terms of publications and citations per year, especially in China and the USA in last 10 years (Figs. 1 and 2, data collected from web of science). Australia has followed the trend in China and the USA, with investigation on CRISPR-Cas growing steadily. Plant sciences, biotechnology on applied microbiology, and biochemistry of molecular biology are top three topics related to plant genome editing by CRISPR-Cas around the world.

The fundamental breakthrough CRISPR-Cas system has tremendous potential to manipulate gene expression for crop improvement and food production. New technologies and applications, based on CRISPR-Cas, have been rapidly 
Figure 1. Trends of publications on plant genome editing by CRISPR-Cas from 2011 to 2020.
Trends of publications from 2011 to 2020

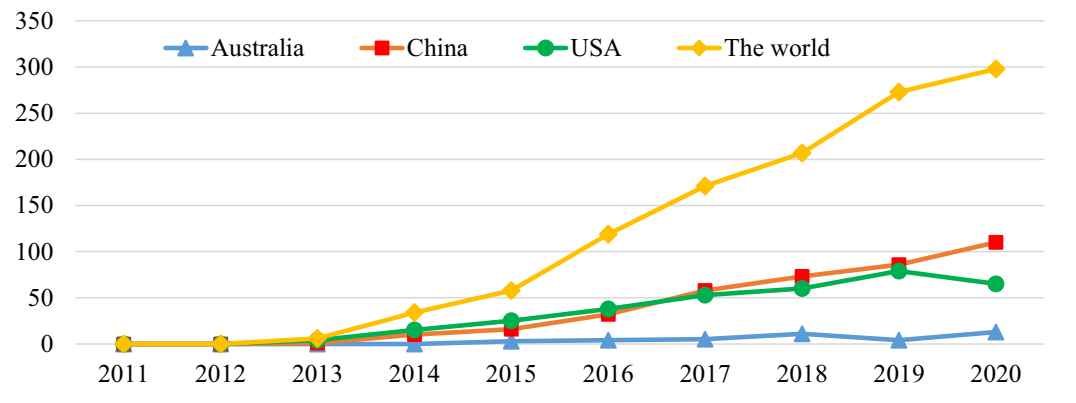

developed. For example, base editing, including cytosine base editors (CBEs) and adenine base editors (ABEs), introduces desired point mutations in a target region (Mishra et al. 2020). Many reviews on CRISPR-Cas system have been reported in recent years; in the present review, we focus on progress in plant genome editing and regulation of CRISPR-edited plants in Australia.

The regulations on plant genome editing in Australia Regulatory approaches to gene editing might broadly be divided into those that focus on the final product and those that are more concerned with the process. In summary, Australia has moved to adopt a position similar to jurisdictions including the USA, Brazil, and Argentina, where if no foreign DNA (genes or genetic material) is present in a genome-edited variety then that variety will not be subject to the regulatory oversight afforded to a genetically modified organisms (GMOs) (Eriksson et al. 2019; Mallapaty 2019; Thygesen 2019).

Legislation on regulating GMOs Within the Commonwealth of Australia, gene technologies and related biotechnologies are regulated under a nationally consistent gene technology regulatory scheme. Australia's regulatory scheme is a prohibitory scheme, meaning all work with GMOs (i.e. import, research, commercial release, manufacture, or production) is prohibited unless the dealing is licensed or falls under another exception. Thus, to understand the regulation of gene-edited plants, it is necessary to understand what is classified as a GMO. This scheme is comprised of the Gene Technology Act 2000 (Legislation 2016a) and Gene Technology Regulations 2001(Legislation 2016b), along with corresponding laws of the States and Territories. The Gene Technology Regulator (the Regulator) is an independent statutory office holder that works for the Office of Gene Technology Regulator (OGTR) and is responsible for governing the GT Act. The objective of the GT Act 2000 is to protect the health and safety of people, and to protect the environment, by identifying risks posed by or as a result of gene technology, and by managing those risks through regulating certain dealings with GMOs (GT Act 2000, Section 3). The key operative terms in the Act are 'gene technology', "any technique for the modification of genes of other genetic material", and 'GMO', "an organism that has been modified by gene technology". The terminology "gene technology" was deliberately worded broadly to prevent it from becoming outdated as new gene technologies arose. The GT Act 2000 regulates work with all GMOs (including microbes, plants, and animals) both in contained facilities and when released into the environment.

Updated legislation on genome editing in Australia There has been ongoing debate in Australia surrounding the regulation of organisms developed by gene editing techniques. Regular reviews and amendments are made to both the GT Act 2000 and GT Regulations 2001 to keep pace with scientific advances in the field. Within the GT Regulations 2001, 'Techniques that are not gene technology' and 'Organisms
Figure 2. Trends of citations on plant genome editing by CRISPR-Cas from 2011 to 2020.
Trends of citations from 2011 to 2020

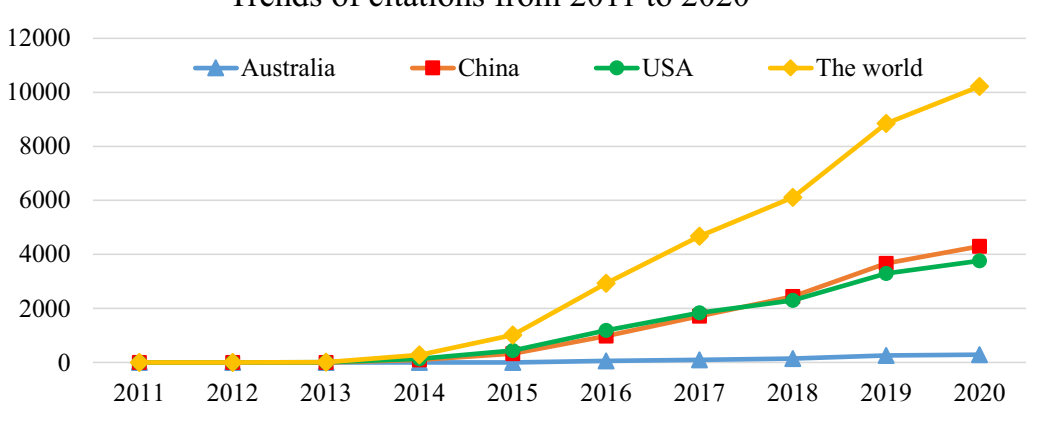


that are not GMOs' are listed under Schedule 1A and Schedule 1, respectively. As of the 8 October 2019, amendments were made to Schedule 1 to clarify the scope of regulation around organisms that are not GMOs. To this list, organisms modified through unguided repair of site-directed nuclease (SDN) activity (also known as SDN-1 organisms) (Fig. 3) were excluded from regulation as GMOs. For an organism to undergo unguided repair means that no nucleic acid template was added to the cells to guide genome repair following SDN application. Therefore, any organisms modified through SDN-1 are no longer classified as GMOs provided that no nucleic acid template was added to the cells to guide homology-directed repair, and the organism has no other traits from gene technology (for example the Cas9 transgene or expressed SDN protein). It is the proponent's responsibility to ensure that these requirements are met, and hence, they are complying with the law.

In the 2019 amendment of the GT Regulations a new schedule, Schedule 1B, "Organisms that are genetically modified organisms", was added. Schedule 1B classifies (Fig. 3) organisms modified by oligonucleotide-directed mutagenesis (ODM) as GMO as well as organisms modified by repair of single-strand or double-strand breaks of genomic DNA induced by a site-directed nuclease using template directed repair to generate a small number of nucleotide changes (SDN2 ), or template directed repair with a longer template to introduce sequences (SDN-3), such as a gene or other sequence of genetic material. These amendments clarified that organisms developed by the above techniques are classed as GMOs and as such, the dealings must meet the regulations set out in the GT Act 2000. In conclusion, under the current regulatory scheme, CRISPR-edited plants that are classified as SDN-1 are not subject to the strict regulations applied to GMOs and are equivalent to other traditionally bred plant varieties.

Case studies on plant genome editing in Australia In this section, we highlight the potential applications and progress of plant genome editing in several selected plant species that are of interest from an Australia perspective. While there are a broad range of plant species that could be described, we focus on several of interest either from an economic, sustainability, or fundamental research perspective as illustrative case studies. Economically, agricultural commodities are of significant value to Australian, worth over AUD \$60 billion in 2019 to 2020 (Snapshot of Australian Agriculture 2021, https://doi. org/10.25814/rxjx-3g23), with around half of that originating from plants, including broadacre crops, fruits and nuts, and vegetables (Fig. 4). Grains are typically considered the second most profitable component of the Australian agriculture industry (after livestock), constituting over a quarter of the industry's gross value. Approximately $70 \%$ of agricultural produce is exported (https://doi.org/10.25814/rxjx-3g23); thus, regulation and attitudes towards gene editing in other countries will also remain an important consideration in Australia.

In the past thousands of years, both natural selection and artificial selection were used to obtain genomic variants. Many crop plants have undergone extensive genetic changes during human domestication (Sedeek et al. 2019). When combined with the knowledge gained from gene mapping, gene editing provides the ability to more specifically target genes of interest and hence affect their function in order to much more
Figure 3. Current (2021) Australian regulatory status of organisms developed via gene editing techniques, natural mutations and mutagenesis.

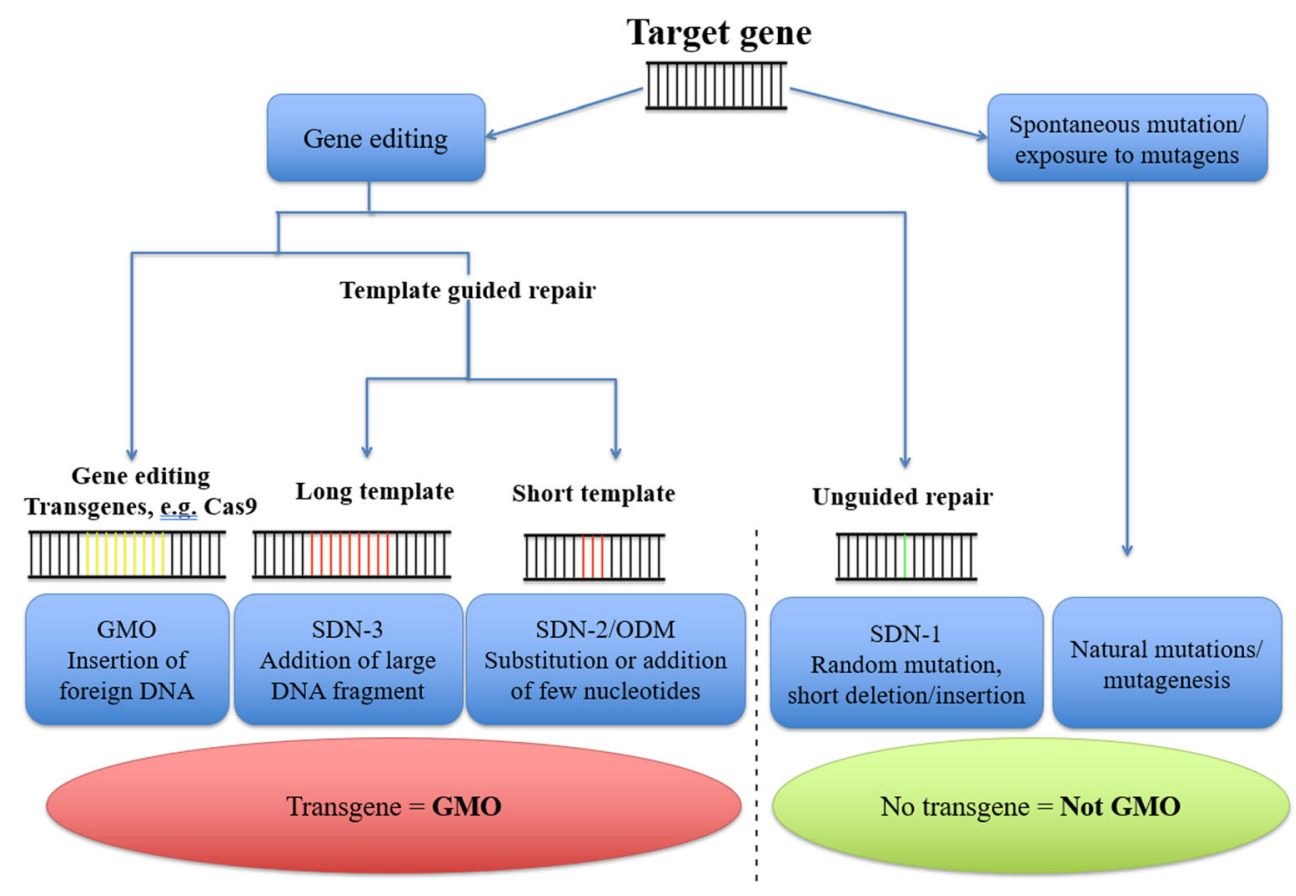


Figure 4. Breakdown of Australia agricultural commodities as a proportion of the $\$ 60$ billion total gross value for the 2019-2020 financial year.

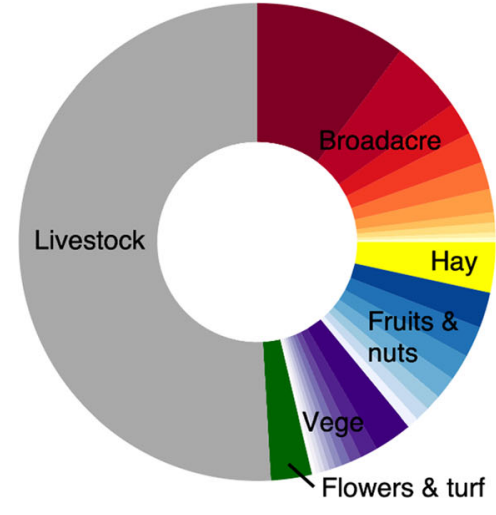

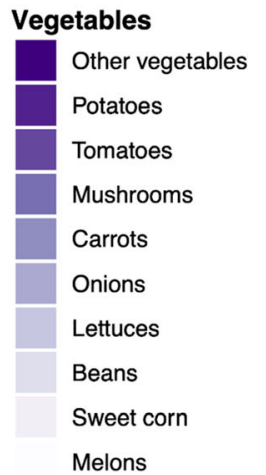

rapidly develop new lines that meet specific agronomic, product quality, or environmental requirements. Globally, there are common traits of interest targeted to help agriculture remains sustainable and productive in a changing climate and under increasing pressure from a growing global population. A review published by Zhang et al. (2018a) provides a summary of a range of recent crop traits across multiple species that have been improved by genome-editing techniques. Targeted traits include but are not limited to improving disease resistance and drought tolerance, increasing yield, creating herbicide resistance, and modifying nutritional profiles.

Cereals-wheat, barley, and sorghum Cereal grains provide more food energy than any other type of crops in the world (Awika 2011). Rice, corn, wheat, barley, and sorghum are generally the top five most important crops among cereals in terms of total production around the world. Wheat and barley are the main crops grown in the winter season, while sorghum is the top crop grown in summer season in Australia. To match the demand from the increasing global population, cereal production has to be improved drastically in near future (Hickey et al. 2019). Precise genetic modification for improvement crop traits especially CRISPR-Cas has drawn tremendous attention (Tachibana 2019). Investigation has been undertaken for genome editing on wheat (Borisjuk et al. 2019; Okada et al. 2019), barley (Lawrenson et al. 2015) and sorghum in Australia (Liu et al. 2019).

Hybrids are used extensively in cereals such as maize and rice to enhance crop yields, capitalising on the phenomenon of heterosis or hybrid vigour. However, it has been challenging to develop commercial hybrids in wheat (Triticum aestivum) due to wheat's strong inbreeding habit. With CRISPR-Cas9 biotechnology, the wheat male fertility gene $M s 1$ has been edited, resulting in complete male sterility in wheat cultivars Fielder and Gladius (Okada et al. 2019). This research has paved the way to wheat hybrids development for increasing yield. Borisjuk et al. (2019) has summarized recent successes in genetic manipulation for wheat improvement of yield, nutritional value, and resistance to various biotic and abiotic stresses. The edited genes demonstrate stable inheritance in multiple generations and transgene-free plants have been segregated from progenies in major crops including barley and sorghum. The HvPM19 gene was targeted in barley (Lawrenson et al. 2015). The cinnamyl alcohol dehydrogenase (CAD) and phytoene desaturase (PDS) genes were investigated in sorghum (Liu et al. 2019). With a green light on plant editing by CRISPR-Cas in Australia, genome editing in cereals would have broad applications for basic research and applied science in future (Liu et al. 2020).

Horticultural fruits and nuts-grape In Australia, grapes contribute a major component to the horticultural industry, with a value close to $\$ 1.5$ billion per annum, including around twothirds in wine production and one-third of that value from other uses. Grapes, like many perennial fruit and nut trees, present challenges for conventional breeding because of long generation times and high heterozygosity. Cultivation of desirable varieties often requires clonal propagation to preserve traits. Vitis vinifera subsp. Vinifera, or modern grape vine, is thought to be the world's oldest cultivate fruit crop, with the dozen or so iconic modern varietals derived from domestication 8,000 years ago. The names of centuries-old varieties are well-known and trusted by consumers, which are another obstacle to breeding new varieties with conventional methods, as these new breeds lack name recognition (McCutcheon et al. 2009). By contrast, propagation of grape through tissue culture offers opportunities for gene editing and potentially regeneration of clones that could be deployed in the industry without the affecting varietal labelling.

For grape, traits of interest include fruit quality, for example, aroma, colour, flavour, and size, as well as biotic and abiotic resistance, flowering control, and berry development. In Australia, the wine industry is facing potential challenges as changing climates threaten ongoing suitability of traditional grape growing regions, and sustainability issues, such as water and nutrient use, are also priorities. Several studies have demonstrated successful gene editing in grape and regeneration of clonal plantlets with modified traits. Transformation and regeneration of callus derived from somatic embryogenesis has been successful in grape, and have been used, for example, to 
modify tartaric acid metabolism by mutating L-idonate dehydrogenase using CRISPR-Cas9 (Ren et al. 2016). Other works have used CRISPR/Cas9 to increase resistance to Botrytis cinerea by mutating VvWRKY52 (Wang et al. 2018); and to study downy mildew resistance (Li et al. 2020). Various efforts have optimized editing by targeting VvPDS (phytoene desaturase) (Nakajima et al. 2017; Ren et al. 2019), and others have demonstrated direct delivery or editing reagents using CRISPR-Cas9 ribonucleoproteins (Malnoy et al. 2016; Osakabe et al. 2018). As technologies continue to advance, including tissue culture free gene editing, there will be many opportunities for grape improvement. Given the very limited genetic variation between most modern grape varietals, some have suggested that epigenetic difference could underly 'terroir' or location-specific difference in quality traits (Xie et al. 2017; Varela et al. 2021). The same technologies used to edit the genome can also be repurposed for epi-genome editing, an alternative route for future grape improvement.

Natural fibre crops-cotton Worth on average AUD \$2 billion annually, cotton lint and cotton seed are Australia's third largest agricultural export, contributing to a significant proportion of the Australian agricultural commodities gross value, as well as being the lifeblood to many regional farming economies and communities. As a product, cotton is a renewable resource, and unlike synthetic fabrics, it is biodegradable. To be able to survive and compete in a heavily subsidized international market, Australian cotton farmers need high yields and low production costs. The best ways to meet these needs are through utilization of efficient farm management and the production of improved commercial lines. In 1996, GM cotton first began being grown commercially on Australian farms. Now, more than $99 \%$ of the cotton grown here contains herbicide tolerance (Roundup Ready), resistance to the major caterpillar pest Helicoverpa spp. (Bt cotton), or both.

Current cotton breeding methods are extremely slow, taking up to 10 years from initial crossing to the release of new commercial lines. These methods have previously been successful in breeding greater water efficient (the most water efficient cotton industry in the world) and insect and herbicide-tolerant cotton into high-yielding and high-quality varieties. However, harnessing new genome editing technologies, in particular the CRISPR/Cas9 system, would allow for an increased range of cultivars with stacked traits of interest, available to farmers in a drastically reduced timeframe. In 2017, it was demonstrated that CRISPR-Cas9 could be used to deliver targeted mutagenesis of the cotton genome with high efficiency and high specificity through agrobacterium-mediated transformation (Chen et al. 2017; Gao et al. 2017; Li et al. 2017). This technology has since been used on a variety of traits. Understanding cotton fibre initiation and development is of high importance for yield and quality advancement. Li et al. (2017) knocked out a MYB-25like transcription factor in cotton, resulting in a fibreless mutation without other phenotypic traits being changed. Improving cotton's resistance to both biotic and abiotic stress is another prospect made possible by genome editing. Knocking out the 14-3-3d gene through CRISPR/Cas9 technology significantly increased crop resistance to Verticillium dahlia, a destructive fungal pathogen (Zhang et al. 2018b). A significantly enhanced total number of lateral roots and total root surface area were found under both normal and nitrogen deficient conditions, following the CRISPR-Cas9 knockout of the arg gene (Wang et al. 2017). This may lead to improvements in cotton's water and nutrient uptake, strengthening tolerance to other abiotic factors and hence boosting its environmental adaptability.

Using CRISPR-Cas9, the Australian cotton industry could be further improved by targeting traits related to lint yield (bolls per plant, boll weights, lint percentage, seed index), fibre quality (fibre length, strength, micronaire), disease resistance and drought tolerance, followed by stacking these traits with the best available pest and herbicide tolerance genes. Utilizing advancing biotechnology in cotton production will lead to a range of environmental, social and economic benefits including but not limited to, dramatic reductions in insecticide and herbicide use, reduced soil tillage leading to better overall soil health, decreased labour and fuel usage, and improved farm worker and neighbor safety.

Model species- $N$. benthamiana Model crop species play an important role as they assist researchers in deciphering specific gene function with efficient transformation and fast testing. Model crops have also been used to advance CRISPR-Cas9 methodologies, for example, multiplexed genome editing of important agronomic traits simultaneously. Nicotiana benthamiana is an important model species with the lab strain "LAB" commonly used for plant genome editing research. $N$. benthamiana is also used by biotechnology companies all around the world (Bally et al. 2018). This species has an exclusively Australian natural distribution (Kelly et al. 2013). N. benthamiana grows in six geographic habitat zones including deserts or mountain areas in Australia. Based on state or territory of the collection site, researchers named the discovered species as Northern Territory (NT), North-Western Australia (NWA), Western Australia (WA), Queensland (QLD), and South Australia (SA). These wild strains are in contrast to the LAB strain, and show diversity in plant form, leaf shape, hercogamy, flower size, and seed size. Therefore, certain attributes of wild $N$. benthamiana species in Australia may be helpful for further discovery and applied research (Bally et al. 2018).

$N$. benthamiana is a complex allotetraploid with a genome including 19 chromosomes. Hence, both genomic and transcriptomic research has been slow due to its large genome 
(3.1 Gb). Two independently assembled draft genome sequences became available to benefit the research community in 2012 (Bombarely et al. 2012; Naim et al. 2012), with sequencing work ongoing today. $N$ benthamiana has been instrumental in discoveries about viral defence and RNAi. Gene editing will further assist these research directions. Researchers have used $N$ benthamiana to develop new tissue culture-free gene editing methodologies (Maher et al. 2020; Ellison et al. 2020). $N$ benthamiana can also be used as a 'biofactory' for the production of biopharmaceuticals including antibodies (Bally et al. 2018). The most recent potential application of $N$. benthamiana could be related to Covid-19 vaccine production. Future gene editing targets of interest include those that might further aid protein production. For example, RDR6 gene knockout by CRISPR-Cas9 enabled edited plants to express larger amounts of recombinant proteins than wild-type plants which, therefore, could be useful for recombinant protein production (Matsuo and Atsumi 2019).

Prospects and challenges of plant genome editing The rapid pace of technological innovation and the willingness of regulators to accommodate new approaches suggest that the future is bright for genome editing in Australia. That said, being an exporter of agricultural goods, it is not only Australian regulators who may throw challenges for deploying the technology. For example, wheat is one of Australia's major agricultural exports, shipping around $70 \%$ of the annual harvest abroad. Thus, regulators in other countries will continue to have a significant influence on activities locally, and differences in regulation (Menz et al. 2020) have the potential to raise problems in the coming years. There also remain several technical limitations of current technologies and several methodological and societal challenges loom on the horizon.

Delivery of gene editing reagents and transformation The biggest bottleneck from a technological point of view remains the efficient delivery of gene editing reagents into plant regenerative cells. Parameters such as vector constructions, transformation methods, transgene integration, and inheritance of transgene need to be carefully considered to ensure the efficiency of the successful transformation event (Lee-Yoon Low et al. 2018). This has also been explored in prior studies; gene transfer in the plant can be categorized into two methods: vector-mediated gene transfer and direct gene transfer through physical or chemical reactions (Minocha and Wallace 2000). Some species are amenable to Agrobacterium-mediated transformation of flowers, allowing progeny derived from sexual propagation to be screened for transformants and edits. However, this luxury does not extend to many species beyond Arabidopsis. For most plants, the flower dipping method is not feasible and an explant-derived callus is instead required for transformation and subsequent regeneration. Transformation and regeneration remain challenging and time-consuming in many Australian crops despite decades of research and progress, for example, in cereals such as wheat, barley, and sorghum.

Take sorghum as an example, as the fifth most significant cereal in the world, it is also the major summer grain crop for most regions in Australia. The first transgenic sorghum was achieved through Agrobacterium-mediated transformation with $2.12 \%$ transformation efficiency in 2000 (Zhao et al. 2000). In addition to the Agrobacterium method, Australian researchers (including ourselves) have established efficient particle bombardment systems for sorghum. Up to $20.7 \%$ transformation efficiency was obtained via a particle delivery system using sorghum Tx430 immature embryos (Liu and Godwin 2012). In 2015, an optimized sorghum tissue culture system was developed, and the main impediments were optimized by adjusting the concentrations of various plant growth regulators, chemicals and hormones in each medium. The optimal age of embryogenic callus for regeneration ability was at two weeks after initiation (Liu et al. 2015).

Moreover, even within species that have become routinely transformable, there are often genotype-dependent effects, for instance, in maize and sorghum (Lowe et al. 2016). Recent progress using developmental regulators such as Baby Boom and Wuschel 2 show promise to dramatically improve transformation efficiency, extending the range of varieties that may be transformed (Lowe et al. 2016) or perhaps obliterating the need for tissue culture (Maher et al. 2020). Likewise, viral carriers that efficiently deliver reagents to meristematic tissue could sidestep the need for explant cultures (Ellison et al. 2020). These advances are especially desirable, as many plant species are difficult or impossible to regenerate through tissue culture.

Identifying genomic targets and complex traits Many agricultural plant traits are by their nature complex, affected by many alleles with small but important effects. This poses an additional challenge for effective trait design by gene editing. We need efficient means to stack multiple desirable edits into elite lines to effectively integrate genome editing into breeding programs. One solution is rapidly cycling and stacking of traits introduced sequentially into target germplasm (Hickey et al. 2019). Likewise, improving the multiplex efficiency of transformation may provide a solution to altering complex traits (Mao et al. 2019). A related challenge is identifying genomic regions to target in the first place. The identification of target regions have been facilitated by rapid sequencing and assembly of plant genomes, exemplified by the recent release of wheat and barley pan-genomes (Bolger et al. 2018; Jayakodi et al. 2020). Although new epigenomic approaches to identify the functionally valuable fraction of the genome may expedite these efforts (Crisp et al. 2019; Crisp et al. 2020), to accurately annotate these genomes is seriously lagging behind (Bolger et al. 2018), Hence, the identification of 
gene promoters and other cis-regulatory elements may provide useful editing targets to fine tune gene expression (Rodriguez-Leal et al. 2017; Liu et al. 2021). Likewise, many crop gene annotations are based on functional genetic evidence of orthologous genes from model species such as Arabidopsis. Thus, even when a gene target is identified for editing in a crop species, whether editing leads to the desired phenotypic change is often unpredictable.

Off-targets and eliminating transgenes The precision of genome editing to direct edits to a target of interest is truly astounding. Yet, even the most precise systems still produce unintended consequences elsewhere in the genome on a regular basis. Indels at locations with sequence similarity to the intended target, or "off targeting", is undesirable as it could lead to detrimental traits. However, these might be easily segregated away in many cases or selected against during initial screening of transgenic lines. More troublesome is the potential for the transgenes encoding the gene editing components to remain after attempts to segregate these away. In Australia, SDN-1 edited plants are exempted from regulation so long as a nucleic acid template was not added, meaning gene editing is permissible so long as the transgenes are lost or segregated out. Sometimes this can be challenging especially if multiple copies of a construct have integrated into plant genomes or if they have fragmented and integrated as smaller, more difficult to detect pieces, as can occur during biolistic bombardment.

Several methods have been developed to eliminate gene editing constructs from plant genomes once they have completed their work. Using marker genes, for example, DsRED which fluoresces in dry seeds when the transgene construct is still present, has been used to identify the transgene-free CRISPR-edited plants of rice, tomato, and Arabidopsis (Aliaga-Franco et al. 2019). An alternative is direct delivery of purified preassembled Cas9-gRNA ribonucleoproteins (RNPs). For instance, via protoplast transformation, gene editing efficiencies up to $46 \%$ have been achieved in regenerated plants of Arabidopsis, tobacco, lettuce and rice without inserting foreign DNA in the host genome. However, due to incomplete restriction of endonuclease digestion or PCR errors, false-positive outcomes can occur; thus, a more systematic and theoretical analysis is required for the target region. Though NGS can resolve these limitations, the process still can be time-constraining and expensive. Besides, protoplast regeneration is recalcitrant in most plant species. Therefore, additional studies to understand more about protoplast regeneration are required for genome editing and the delivery of effective materials (RNPs or donor DNA) to achieve transgene-free crops (Woo et al. 2015; Lin et al. 2018). Additional methods have been developed to eliminate the CRISPR-Cas9 constructs including, using the cre-loxP system to excise the integrated fragments after editing, antibiotic marker-free transformation strategies through CRISPR-Cas9 genes transient expression in $\mathrm{T}_{0}$, and germline injection of Cas9 protein and guide RNA (Schwartz and Sternberg 2014; Aliaga-Franco et al. 2019; Veillet et al. 2019; Wang et al. 2020). It is more important for vegetatively propagated crops (such as sugarcane and banana) to obtain transgene-free genome editing plants in the $T_{0}$ generation because it is hard to eliminate CRISPR-Cas9 constructs through self-crossing or out-crossing in these species. A simple and effective method of genome editing has been used in wheat in which plants are regenerated from callus cells by transiently expressing CRISPR-Cas9 introduced as DNA or RNA. This transient expression-based genome editing system is highly efficient and specific. It can be used to produce transgene-free and homozygous mutants in the $\mathrm{T}_{0}$ generation (Zhang et al. 2016). Until these methods mature across the range of plant species currently being gene-edited, transgenes will continue to lead to a quandary for researchers and developers as they ponder what lengths they may need to go, to determine no foreign DNA remains in their edited genomes. This might range from simple antibiotic selection, PCR-based amplification to the possibility of whole genome resequencing, a requirement that would render the tremendous promise of genome editing infeasible to many.

The final frontier for genome editing is riding the wave of public (and political) opinion. The public have an important role, whether through acceptance of consumer products, influence on political mandate, or willingness to fund vital research. There is no doubt that this will remain a topical and emotive issue. Gene editing offers tremendous benefits, which could flow to many in need. Educating the public about this complex science is as important as the research itself, so the risks and benefits are understood.

\section{Conclusion}

It is clear that plant genome editing technology is a key tool to unleash crop productivity, as well as human and planetary health benefits. In many jurisdictions, including Australia, the fact that certain gene editing approaches are not regulated as GM means, there is the potential to rapidly deploy these in plant improvement programs. In many cases, the most immediate applications will be the change of one or few traits in already extant elite cultivars. This will be most easily delivered in inbred cultivars (wheat, rice, barley, soybean, pulses, etc.), where any transgene insertion can be segregated from the edit(s) by self-pollination. This is also possible in hybrid crops (maize, sorghum, sugar beet, etc.), although for most applications this will be slowed by the need to introgress edits into both the male and female parent lines. It is more problematic in clonally propagated crops (potatoes, bananas, cassava, most fruit and nut trees, etc.), where segregation is not an option. For these species, DNA-free delivery methods require 
more development and optimization, with a likely outcome of lower editing efficiency.

For the consumer, it is important to ensure there is clarity of regulation and product safety. As was experienced with GM crops, it is a simple matter for activist groups to circulate datafree opinions and anecdotal arguments to create fear of any new technology, particularly when it involves food production (Dinneny 2018; Godwin 2019). There is also a need to consider market access for the products of gene editing and this in itself creates a risk for corporate investment into the technology, particularly for a country like Australia wherein $70 \%$ of our agricultural produce is exported. Many jurisdictions have not yet ruled on gene-edited crops and foods, and this remains problematic for plant breeding companies and researchers. European Union remains a sizable impediment to the certainty of markets for new technologies for sustainable food production.

Acknowledgements We are grateful to Grains Research and Development Corporation (GRDC) for funding the GRDC Better sorghum larger grain project (9176038). P.A.C. is the recipient of an Australian Research Council Discovery Early Career Researcher Award (project number DE200101748) funded by the Australian Government.

\section{Declarations}

Conflict of interest The authors declare no competing interests.

\section{References}

Aliaga-Franco N, Zhang C, Presa S, Srivastava AK, Granell A, Alabadi D, Sadanandom A, Blazquez MA, Minguet EG (2019) Identification of transgene-free CRISPR-edited plants of rice, tomato, and arabidopsis by monitoring DsRED fluorescence in dry seeds. Front Plant Sci 10:1150. https://doi.org/10.3389/fpls.2019.01150

Awika JM (2011) Major Cereal Grains Production and Use around the World. In: Awika JM, Piironen V, Bean S (eds) Advances in cereal science: implications to food processing and health promotion, vol 1089. ACS Symposium Series, pp 1-13

Bally J, Jung H, Mortimer C, Naim F, Philips JG, Hellens R, Bombarely A, Goodin MM, Waterhouse PM (2018) The rise and rise of Nicotiana benthamiana: a plant for all reasons. In: Leach JE. Lindow SE (eds) Ann Rev Phytopathol 56:405-426. https://doi. org/10.1146/annurev-phyto-080417-050141

Bolger ME, Arsova B, Usadel B (2018) Plant genome and transcriptome annotations: from misconceptions to simple solutions. Brief Bioinform 19:437-449. https://doi.org/10.1093/bib/bbw135

Bombarely A, Rosli HG, Vrebalov J, Moffett P, Mueller LA, Martin GB (2012) A draft genome sequence of Nicotiana benthamiana to enhance molecular plant-microbe biology research. Mol PlantMicrobe Interact 25:1523-1530. https://doi.org/10.1094/mpmi-0612-0148-ta

Borisjuk N, Kishchenko O, Eliby S, Schramm C, Anderson P, Jatayev S, Kurishbayev A, Shavrukov Y (2019) Genetic modification for wheat improvement: from transgenesis to genome editing. Biomed Res Int 2019:1-18. https://doi.org/10.1155/2019/6216304
Bortesi L, Fischer R (2015) The CRISPR/Cas9 system for plant genome editing and beyond. Biotechnol Adv 33:41-52. https://doi.org/10. 1016/j.biotechadv.2014.12.006

Chen XG, Lu XK, Shu N, Wang S, Wang JJ, Wang DL, Guo LX, Ye WW (2017) Targeted mutagenesis in cotton (Gossypium hirsutum L.) using the CRISPR/Cas9 system. Sci Rep 7. https://doi.org/10. 1038/srep44304

Crisp PA, Marand AP, Noshay JM, Zhou P, Lu ZF, Schmitz RJ, Springer NM (2020) Stable unmethylated DNA demarcates expressed genes and their cis-regulatory space in plant genomes. Proc Natl Acad Sci 117:23991-24000. https://doi.org/10.1073/pnas.2010250117

Crisp PA, Noshay JM, Anderson SN, Springer NM (2019) Opportunities to use DNA methylation to distil functional elements in large crop genomes. Mol Plant 12:282-284. https://doi.org/10.1016/j.molp. 2019.02.006

Dinneny JR (2018) Seeds of Science Why We Got It So Wrong on GMOs. Science 360:1407-1407. https://doi.org/10.1126/science. aat8772

Ellison EE, Nagalakshmi U, Gamo ME, Huang PJ, Dinesh-Kumar S, Voytas DF (2020) Multiplexed heritable gene editing using RNA viruses and mobile single guide RNAs. Nat Plants 6:620-+. https:// doi.org/10.1038/s41477-020-0670-y

Eriksson D, Kershen D, Nepomuceno A, Pogson BJ, Prieto H, Purnhagen K, Smyth S, Wesseler J, Whelan A (2019) A comparison of the EU regulatory approach to directed mutagenesis with that of other jurisdictions, consequences for international trade and potential steps forward. New Phytol 222:1673-1684. https://doi.org/10.1111/nph. 15627

Gaj T, Gersbach CA, Barbas CF (2013) ZFN, TALEN, and CRISPR/ Cas-based methods for genome engineering. Trend Biotechnol 31: 397-405. https://doi.org/10.1016/j.tibtech.2013.04.004

Gao W, Long L, Tian XQ, Xu FC, Liu J, Singh PK, Botella JR, Song CP (2017) Genome Editing in Cotton with the CRISPR/Cas9 System. Front Plant Sci 8. https://doi.org/10.3389/fpls.2017.01364

Godwin ID (2019) Good Enough to Eat?: Next generation GM crops. Royal Society of Chemistry

Hickey LT, A NH, Robinson H, Jackson SA, Leal-Bertioli SCM, Tester M, Gao C, Godwin ID, Hayes BJ, Wulff BBH (2019) Breeding crops to feed 10 billion. Nat Biotechnol 37:744-754. https://doi. org/10.1038/s41587-019-0152-9

Jayakodi M, Padmarasu S, Haberer G, Bonthala VS, Gundlach H, Monat C, Lux T, Kamal N, Lang DI, Himmelbach A, Ens J, Zhang XQ, Angessa TT, Zhou GF, Tan C, Hill C, Wang PH, Schreiber M, Boston LB, Plott C, Jenkins J, Guo Y, Fiebig A, Budak H, Xu DD, Zhang J, Wang CC, Grimwood J, Schmutz J, Guo GG, Zhang GP, Mochida K, Hirayama T, Sato K, Chalmers KJ, Langridge P, Waugh R, Pozniak CJ, Scholz U, Mayer KFX, Spannagl M, Li CD, Mascher M, Stein N (2020) The barley pangenome reveals the hidden legacy of mutation breeding. Nature 588: 284-289. https://doi.org/10.1038/s41586-020-2947-8

Jinek M, Chylinski K, Fonfara I, Hauer M, Doudna JA, Charpentier E (2012) A programmable dual-RNA-guided DNA endonuclease in adaptive bacterial immunity. Science 337:816-821. https://doi.org/ $10.1126 /$ science. 1225829

Kelly LJ, Leitch AR, Clarkson JJ, Knapp S, Chase MW (2013) Reconstructing the complex evolutionary origin of wild allopolyploid tobaccos (Nicotiana section suaveolentes). Evolution 67:8094. https://doi.org/10.1111/j.1558-5646.2012.01748.x

Lawrenson T, Shorinola O, Stacey N, Li CD, Ostergaard L, Patron N, Uauy C, Harwood W (2015) Induction of targeted, heritable mutations in barley and Brassica oleracea using RNA-guided Cas9 nuclease. Genome Biol 16. https://doi.org/10.1186/s13059-015-0826-7

Lee-Yoon Low S-KY, Kok D-XA, Ong-Abdullah J, Tan N-P, Lai K-S (2018) Transgenic plants: gene constructs, vector and transformation method. New Visions Plant Sci 21. https://doi.org/10.5772/ intechopen.79369 
Legislation FRo (2016a) Gene Technology Act 2000. Federal Register of Legislation, https://www.legislation.gov.au/Details/C2016C00792

Legislation FRo (2016b) Gene Technology Regulations 2001. https:// www.legislation.gov.au/Details/F2016C00615,

Li C, Unver T, Zhang BH (2017) A high-efficiency CRISPR/Cas9 system for targeted mutagenesis in Cotton (Gossypium hirsutum L.). Sci Rep 7. https://doi.org/10.1038/srep43902

Li MY, Jiao YT, Wang YT, Zhang N, Wang BB, Liu RQ, Yin X, Xu Y, Liu GT (2020) CRISPR/Cas9-mediated VvPR4b editing decreases downy mildew resistance in grapevine (Vitis vinifera L.). Hortic Res 7. https://doi.org/10.1038/s41438-020-00371-4

Lin CS, Hsu CT, Yang LH, Lee LY, Fu JY, Cheng QW, Wu FH, Hsiao HCW, Zhang YS, Zhang R, Chang WJ, Yu CT, Wang W, Liao LJ, Gelvin SB, Shih MC (2018) Application of protoplast technology to CRISPR/Cas9 mutagenesis: from single-cell mutation detection to mutant plant regeneration. Plant Biotechnol J 16:1295-1310. https:// doi.org/10.1111/pbi.12870

Liu G, Gilding EK, Godwin ID (2015) A robust tissue culture system for sorghum [Sorghum bicolor (L.) Moench]. S Afr J Bot 98:157-160. https://doi.org/10.1016/j.sajb.2015.03.179

Liu G, Li J, Godwin ID (2019) Genome editing by CRISPR/Cas9 in sorghum through biolistic bombardment. Methods Mol Biol 1931: 169-183. https://doi.org/10.1007/978-1-4939-9039-9 12

Liu G, Massel K, Tabet B, Godwin ID (2020) Biolistic DNA delivery and its applications in sorghum bicolor. Meth Mol Biol 2124:197-215. https://doi.org/10.1007/978-1-0716-0356-7_10

Liu GQ, Godwin ID (2012) Highly efficient sorghum transformation. Plant Cell Rep 31:999-1007. https://doi.org/10.1007/s00299-011$1218-4$

Liu L, Gallagher J, Arevalo ED, Chen R, Skopelitis T, Wu QY, Bartlett M, Jackson D (2021) Enhancing grain-yield-related traits by CRISPR-Cas9 promoter editing of maize CLE genes. Nat Plant 7: 287-294. https://doi.org/10.1038/s41477-021-00858-5

Lowe K, Wu E, Wang N, Hoerster G, Hastings C, Cho MJ, Scelonge C, Lenderts B, Chamberlin M, Cushatt J, Wang LJ, Ryan L, Khan T, Chow-Yiu J, Hua W, Yu M, Banh J, Bao ZM, Brink K, Igo E, Rudrappa B, Shamseer PM, Bruce W, Newman L, Shen B, Zheng PZ, Bidney D, Falco C, Register J, Zhao ZY, Xu DP, Jones T, Gordon-Kamm W (2016) Morphogenic Regulators Baby boom and Wuschel Improve Monocot Transformation. Plant Cell 28: 1998-2015. https://doi.org/10.1105/tpc.16.00124

Maher MF, Nasti RA, Vollbrecht M, Starker CG, Clark MD, Voytas DF (2020) Plant gene editing through de novo induction of meristems. Nat Biotechnol 38:84-89. https://doi.org/10.1038/s41587-019$0337-2$

Mallapaty S (2019) Australian gene-editing rules adopt 'middle ground'. Nature. https://doi.org/10.1038/d41586-019-01282-8

Malnoy M, Viola R, Jung MH, Koo OJ, Kim S, Kim JS, Velasco R, Kanchiswamy CN (2016) DNA-free genetically edited grapevine and apple protoplast using CRISPR/Cas9 ribonucleoproteins. Front Plant Sci 7. https://doi.org/10.3389/fpls.2016.01904

Mao YF, Botella JR, Liu YG, Zhu JK (2019) Gene editing in plants: progress and challenges. Natl Sci Rev 6:421-437. https://doi.org/ 10.1093/nsr/nwz005

Matsuo K, Atsumi G (2019) CRISPR/Cas9-mediated knockout of the RDR6 gene in Nicotiana benthamiana for efficient transient expression of recombinant proteins. Planta 250:463-473. https://doi.org/ $10.1007 / \mathrm{s} 00425-019-03180-9$

McCutcheon E, Bruwer J, Li E (2009) Region of origin and its importance among choice factors in the wine-buying decision making of consumers. Intl J Wine Bus Res 21:212-+. https://doi.org/10.1108/ 17511060910985953

Menz J, Modrzejewski D, Hartung F, Wilhelm R, Sprink T (2020) Genome edited crops touch the market: a view on the global development and regulatory environment. Front Plant Sci 11, 11. https:// doi.org/10.3389/fpls.2020.586027
Minocha SC, Wallace JC (2000) Gene transfer techniques and their relevance to woody plants. In: Jain SM, Minocha SC (eds) Molecular biology of woody plants: volume 2. Springer Netherlands, Dordrecht, pp 1-24. https://doi.org/10.1007/978-94-017-2313-8_1

Mishra R, Joshi RK, Zhao K (2020) Base editing in crops: current advances, limitations and future implications. Plant Biotechnol J 18: 20-31. https://doi.org/10.1111/pbi.13225

Naim F, Nakasugi K, Crowhurst RN, Hilario E, Zwart AB, Hellens RP, Taylor JM, Waterhouse PM, Wood CC (2012) Advanced engineering of lipid metabolism in Nicotiana benthamiana using a draft genome and the V2 viral silencing-suppressor protein. Plos One 7. https://doi.org/10.1371/journal.pone.0052717

Nakajima I, Ban Y, Azuma A, Onoue N, Moriguchi T, Yamamoto T, Toki S, Endo M (2017) CRISPR/Cas9-mediated targeted mutagenesis in grape. Plos One 12. https://doi.org/10.1371/journal.pone. 0177966

Okada A, Arndell T, Borisjuk N, Sharma N, Watson-Haigh NS, Tucker EJ, Baumann U, Langridge P, Whitford R (2019) CRISPR/Cas9mediated knockout of Ms1 enables the rapid generation of malesterile hexaploid wheat lines for use in hybrid seed production. Plant Biotechnol J 17:1905-1913. https://doi.org/10.1111/pbi. 13106

Osakabe Y, Liang ZC, Ren C, Nishitani C, Osakabe K, Wada M, Komori S, Malnoy M, Velasco R, Poli M, Jung MH, Koo OJ, Viola R, Kanchiswamy CN (2018) CRISPR-Cas9-mediated genome editing in apple and grapevine. Nat Protoc 13:2844-2863. https://doi.org/ 10.1038/s41596-018-0067-9

Ren C, Liu XJ, Zhang Z, Wang Y, Duan W, Li SH, Liang ZC (2016) CRISPR/Cas9-mediated efficient targeted mutagenesis in Chardonnay (Vitis vinifera L.). Sci Rep 6. https://doi.org/10.1038/ srep32289

Ren FR, Ren C, Zhang Z, Duan W, Lecourieux D, Li SH, Liang ZC (2019) Efficiency optimization of CRISPR/Cas9-mediated targeted mutagenesis in grape. Front Plant Sci 10. https://doi.org/10.3389/ fpls.2019.00612

Rodriguez-Leal D, Lemmon ZH, Man J, Bartlett ME, Lippman ZB (2017) Engineering quantitative trait variation for crop improvement by genome editing. Cell 171:470-+. https://doi.org/10.1016/j.cell. 2017.08.030

Schwartz HT, Sternberg PW (2014) Transgene-free genome editing by germline injection of CRISPR/Cas RNA. In: Doudna JA, Sontheimer EJ (eds) Use of Crispr/Cas9, Zfns, and Talens in Generating Site-Specific Genome Alterations, vol 546. Methods in Enzymology, pp 441-457. https://doi.org/10.1016/b978-0-12801185-0.00021-0

Sedeek KEM, Mahas A, Mahfouz M (2019) Plant genome engineering for targeted improvement of crop traits. Front Plant Sci 10, 10. https://doi.org/10.3389/fpls.2019.00114

Strzyz P (2020) CRISPR-Cas9 wins Nobel. Nat Rev Mol Cell Biol 21: 714-714. https://doi.org/10.1038/s41580-020-00307-9

Tachibana C (2019) Beyond CRISPR: What's current and upcoming in genome editing. Science 365:1481-1483

Thygesen P (2019) Clarifying the regulation of genome editing in Australia: situation for genetically modified organisms. Transgenic Res 28:151-159. https://doi.org/10.1007/s11248-019-00151-4

Varela A, Ibanez VN, Alonso R, Zavallo D, Asurmendi S, Talquenca SG, Marfil CF, Berli FJ (2021) Vineyard environments influence Malbec grapevine phenotypic traits and DNA methylation patterns in a clone-dependent way. Plant Cell Rep 40:111-125. https://doi. org/10.1007/s00299-020-02617-w

Veillet F, Perrot L, Chauvin L, Kermarrec MP, Guyon-Debast A, Chauvin JE, Nogue F, Mazier M (2019) Transgene-free genome editing in tomato and potato plants using agrobacterium-mediated delivery of a CRISPR/Cas9 cytidine base editor. Int J Mol Sci 20. https://doi.org/10.3390/ijms20020402 
Wang N, Arling M, Hoerster G, Ryan L, Wu E, Lowe K, Gordon-Kamm W, Jones TJ, Chilcoat ND, Anand A (2020) An efficient gene excision system in maize. Front Plant Sci 11. https://doi.org/10.3389/ fpls.2020.01298

Wang XH, Tu MX, Wang DJ, Liu JW, Li YJ, Li Z, Wang YJ, Wang XP (2018) CRISPR/Cas9-mediated efficient targeted mutagenesis in grape in the first generation. Plant Biotechnol J 16:844855. https://doi.org/10.1111/pbi.12832

Wang YL, Meng ZG, Liang CZ, Meng ZH, Wang Y, Sun GQ, Zhu T, Cai YP, Guo SD, Zhang R, Lin Y (2017) Increased lateral root formation by CRISPR/Cas9-mediated editing of arginase genes in cotton. Sci China-Life Sci 60:524-527. https://doi.org/10.1007/s11427017-9031-y

Woo JW, Kim J, Il Kwon S, Corvalan C, Cho SW, Kim H, Kim SG, Kim ST, Choe S, Kim JS (2015) DNA-free genome editing in plants with preassembled CRISPR-Cas9 ribonucleoproteins. Nat Biotechnol 33:1162-U1156. https://doi.org/10.1038/nbt.3389

Xie HH, Konate M, Sai N, Tesfamicael KG, Cavagnaro T, Gilliham M, Breen J, Metcalfe A, Stephen JR, De Bei R, Collins C, Lopez CMR (2017) Global DNA methylation patterns can play a role in defining terroir in grapevine (Vitis vinifera cv. Shiraz). Front Plant Sci 8. doi: https://doi.org/10.3389/fpls.2017.01860

Zhang Y, Liang Z, Zong Y, Wang YP, Liu JX, Chen KL, Qiu JL, Gao CX (2016) Efficient and transgene-free genome editing in wheat through transient expression of CRISPR/Cas9 DNA or RNA. Nature Comm 7. https://doi.org/10.1038/ncomms12617

Zhang Y, Massel K, Godwin ID, Gao C (2018a) Applications and potential of genome editing in crop improvement. Genome Biol 19:210. https://doi.org/10.1186/s13059-018-1586-y

Zhang ZN, Ge XY, Luo XL, Wang P, Fan Q, Hu G, Xiao JL, Li FG, Wu JH (2018b) Simultaneous editing of two copies of Gh14-3-3d confers enhanced transgene-clean plant defense against Verticillium dahliae in allotetraploid upland cotton. Front Plant Sci 9. https:// doi.org/10.3389/fpls.2018.00842

Zhao ZY, Cai TS, Tagliani L, Miller M, Wang N, Pang H, Rudert M, Schroeder S, Hondred D, Seltzer J, Pierce D (2000) Agrobacteriummediated sorghum transformation. Plant Mol Biol 44:789-798

Zhu HC, Li C, Gao CX (2020) Applications of CRISPR-Cas in agriculture and plant biotechnology (vol 21, pg 661, 2020). Nat Rev Mol Cell Biol 21:782. https://doi.org/10.1038/s41580-020-00312-y 